\title{
Mineralização do nitrogênio de plantas de cobertura, solteiras e consorciadas, depositadas sobre um solo com histórico de cultivo de cebola ${ }^{1}$
}

\author{
Roberta Pereira Martins ${ }^{2}$, Jucinei José Comin ${ }^{3}$ Luciano Colpo Gatibonit, Cláudio Roberto Fonseca Soares ${ }^{3}$, \\ Rafael da Rosa Couto ${ }^{5}$, Gustavo Brunetto ${ }^{6}$
}

http://dx.doi.org/10.1590/0034-737X201461040020

\section{RESUMO}

A decomposição das plantas de cobertura de inverno, depositadas sobre o solo, podem aumentar a disponibilidade de formas de nitrogênio $(\mathrm{N})$, durante o ciclo da cebola. O trabalho objetivou avaliar a mineralização de $\mathrm{N}$ da massa de plantas de cobertura, solteiras e consorciadas, em um solo com histórico de cultivo de cebola. Porções de solo foram coletadas, preparadas, acondicionadas em recipientes de acrílico. Matéria seca de aveia preta, centeio, nabo-forrageiro, aveia preta+nabo-forrageiro e centeio+nabo-forrageiro, foram adicionadas sobre a superfície do solo e incubadas por 90 dias. No tempo zero e aos 18, 36, 54, 72 e 90 dias após a incubação (DAI), as porções de solo foram amostradas e determinados os teores de $\mathrm{N}$ total, $\mathrm{N}_{-} \mathrm{NO}_{3}{ }^{-}$e $\mathrm{N}-\mathrm{NH}_{4}{ }^{+}$de cada uma. Calcularam-se os valores de $\mathrm{N}$ mineral, $\mathrm{N}$ mineral líquido, $\mathrm{N}$ mineralizado e $\mathrm{N}$ total- $\mathrm{N}$ mineralizado. Os maiores teores de $\mathrm{N}_{-} \mathrm{NH}_{4}{ }^{+}$foram observados nas porções de solo com a deposição de massa de nabo-forrageiro e do consórcio centeio+nabo-forrageiro. Os maiores teores de $\mathrm{N}-\mathrm{NO}_{3}{ }^{-} \mathrm{e}$ $\mathrm{N}$-mineral dos 36 até os 90 DAI e de N-mineralizado dos 18 até os 92 DAI foram observados nas porções de solo com a deposição de massa de centeio + nabo-forrageiro. A taxa de mineralização foi positiva em todas as amostras do solo com deposição de massa de centeio e nabo-forrageiro, e dos consórcios aveia preta+nabo-forrageiro e centeio+naboforrageiro e negativa aos 18 e 72 DAI, nas porções de solo com deposição de massa de aveia. Os resíduos de naboforrageiro e do consórcio centeio+nabo-forrageiro apresentaram o maior potencial de mineralização.

Palavras-chave: decomposição de resíduos, N-mineral, Allium cepa L.

\section{ABSTRACT}

\section{Nitrogen mineralization of cover plant litter, intercropped or not, in a soil with a history of onion plantation}

The decomposition of winter cover plants on the soil surface can increase nitrogen $(\mathrm{N})$ availability during the onion crop cycle. The objective of this study was to evaluate $\mathrm{N}$ mineralization of cover plant litter, intercropeed or not, in a soil with a history of onion plantation. Soil was collected, prepared, placed in acrylic containers. Dry mass of black oats, rye, oilseed radish, black oats + oilseed radish and rye + oilseed radish were added into soil surface and incubated for 90 days. Soil was sampled and contents of total $\mathrm{N}, \mathrm{NO}_{3}^{-}-\mathrm{N}$ and $\mathrm{NH}_{4}^{+}-\mathrm{N}$ were determined at time zero and at 18, 36, 54,72 and 90 days after incubation. Values of mineral $\mathrm{N}$, net mineral N, mineralized $\mathrm{N}$ and total $\mathrm{N}$ - mineralized $\mathrm{N}$ were

\footnotetext{
Recebido para publicação em 06/02/2013 e aprovado em 19/11/2013.

${ }^{1}$ Parte da dissertação de mestrado do primeiro autor. Trabalho financiado com recursos parciais da Fapesc.

${ }^{2}$ Engenheira Agrônoma, Mestre. Programa de Pós-Graduação em Agroecosssistemas, Centro de Ciências Agrárias, Universidade Federal de Santa Catarina, Rodovia Admar Gonzaga, 1346, 88034-000, Florianópolis, Santa Catarina, Brasil. agrobeca@yahoo.com.br

${ }^{3}$ Engenheiro Agrônomo, Doutor. Programa de Pós-Graduação em Agroecosssistemas, Centro de Ciências Agrárias, Universidade Federal de Santa Catarina, Rodovia Admar Gonzaga, 1346, 88034-000, Florianópolis, Santa Catarina, Brasil. j.comin@ufsc.br; crfsoares@gmail.com

${ }^{4}$ Engenheiro Agrônomo, Doutor. Centro de Ciências Agroveterinárias, Universidade do Estado de Santa Catarina, Avenida Luiz de Camões, 2090, 88.520-000, Lages, Santa Catarina, Brasil. Igatiboni@gmail.com

${ }^{5}$ Tecnólogo em Agropecuária, Mestre. Centro Tecnológico, Universidade Federal de Santa Catarina, Programa de Pós-graduação em Engenharia Ambiental, 88040-970, Florianópolis, Santa Catarina, Brasil.rrccouto@hotmail.com

${ }^{6}$ Engenheiro Agrônomo, Doutor. Programa de Pós-Graduação em Ciência do Solo, Centro de Ciências Rurais, Universidade Federal de Santa Maria, Avenida Roraima, bairro, 97105-900, Santa Maria, Rio Grande do Sul, Brasil. brunetto.gustavo@gmail.com
} 
calculated. The highest contents of $\mathrm{NH}_{4}^{+}$-N were found in the soil with the deposition of oilseed radish litter and rye + oilseed radish intercrop. The greatest contents of $\mathrm{NO}_{3}-\mathrm{N}$ and mineral $\mathrm{N}$ from 36 to 90 days after incubation and of mineralized $\mathrm{N}$ from 18 to $92 \mathrm{DAI}$ were found in the soil with the rye + oilseed radish litter deposition. Mineralization rate was positive in all soil samples with deposition of rye and oilseed radish litter, and black oats + oilseed radish and rye + oilseed radish intercrops, and negative on 18 and 72 days after incubation in the soil with deposition of black oats litter. The oilseed radish litter and rye + oilseed radish intercrop displayed the greatest potential for mineralization.

Key words: Allium cepa L., decomposition, mineral $\mathrm{N}$

\section{INTRODUÇÃO}

O estado de Santa Catarina (SC) possui a maior área cultivada com cebola (Allium cepa L.) do Brasil. O cultivo é realizado sob Sistema de Cultivo Convencional (SCC) e, em menor escala, sob Sistema Plantio Direto (SPD), no qual espécies de plantas de cobertura da família das gramíneas, entre elas a aveia preta (Avena sativa L.) e o centeio (Secale cereale L.), e das crucíferas, principalmente o nabo-forrageiro (Raphanus sativus L.), são cultivadas solteiras ou consorciadas durante o outono e inverno. No final do inverno e início da primavera, antes do transplante das mudas de cebola, a parte aérea das espécies de plantas de cobertura é depositada sobre a superfície do solo. Com isso, espera-se maior proteção da superfície do solo contra o impacto das gotas da chuva, o que, por consequência, diminui a erosão hídrica e a incidência de plantas espontâneas e aumenta o armazenamento de água no perfil do solo, mas também, a mineralização de nutrientes, entre eles o nitrogênio $(\mathrm{N})$, durante o processo de decomposição do material vegetal, o que pode aumentar sua disponibilidade para as culturas (Flower et al., 2011; Souza et al., 2013).

O carbono (C) orgânico dos resíduos de espécies de plantas de cobertura, solteiras ou consorciadas, depositados na superfície do solo é utilizado como fonte de energia pelos micro-organismos, como fungos e bactérias, liberando parte do $\mathrm{CO}_{2}$ para a atmosfera; enquanto parte do N, contido no material vegetal, pode ser mineralizada, incrementando as suas formas minerais, como o amônio $\left(\mathrm{N}-\mathrm{NH}_{4}^{+}\right)$e o nitrato $\left(\mathrm{N}^{-\mathrm{NO}_{3}}{ }^{-}\right)$no solo (Janssens et al., 2010), que podem ser absorvidas pela cebola ao longo do seu ciclo. No entanto, a decomposição da massa e, por consequência, a mineralização de $\mathrm{N}$ são dependentes de condições ambientais, como, por exemplo, a umidade e a temperatura do solo, os valores de $\mathrm{pH}$ do solo e as características químicas do material vegetal, especialmente, do teor total de Ne C (Dilly et al., 2003; Sylvia et al., 2004) e os teores de celulose e hemicelulose (Meier et al., 2006; Sanchez, 2009), lignina (Sanchez, 2009; Vahdat et al., 2011); e polifenóis totais (Joanisse et al., 2008; Thorpe et al., 2011). O processo de decomposição também é influencia- do pelas relações celulose/lignina, lignina/N, polifenóis/ $\mathrm{N}$ e C/N (Trinsoutrot et al., 2000; Meier et al., 2006; Sanchez, 2009; Mohanty et al., 2011). Em geral, os microorganismos decompositores não conseguem quebrar as estruturas para retirar o $\mathrm{C}$ de resíduos muito lignificados ou com alta relação $\mathrm{C} / \mathrm{N}$, o que, por consequência, diminui a velocidade de decomposição e, consequentemente, a mineralização de N (Månsson \& Falkengren-Grerup, 2003; Bonanomi et al., 2013).

A aveia preta e o centeio, em geral, apresentam não só baixos teores de $\mathrm{N}$, o que se reflete em alta relação $\mathrm{C} / \mathrm{N}$, mas também, altos teores de lignina (Sá et al., 2001; Séguy et al., 2006). Porém, quando a aveia preta e o centeio são consorciados com o nabo-forrageiro, que apresenta baixa relação $\mathrm{C} / \mathrm{N}$ e baixos teores de lignina, a matéria seca (MS) passa a apresentar uma relação $\mathrm{C} / \mathrm{N}$ intermediária e menores teores de lignina, o que pode favorecer a decomposição e, por consequência, a mineralização de $\mathrm{N}$ (Cabrera et al., 2005). Entretanto, a taxa de mineralização de $\mathrm{N}$ de resíduos dessas espécies, solteiras ou consorciadas, ao longo do ciclo da cebola, na região sul do Brasil, é pouco conhecida. Pode ser estimada, usando-se o método da incubação (Stanford \& Smith, 1972; Camargo et al., 1997; Fioreze et al., 2012), no qual amostras de solo com material vegetal são acondicionadas em recipientes em câmara de incubação, com controle de temperatura, e umidade do solo monitorada. Assim, é possível, ao longo do tempo, simular o ciclo da cultura de interesse econômico, como a cebola, coletando-se amostras de solo e de massa e, posteriormente, determinando-se as formas de $\mathrm{N}$ no solo, especialmente, $\mathrm{N}_{-} \mathrm{NH}_{4}^{+} \mathrm{e} \mathrm{N}-\mathrm{NO}_{3}$, calcular o teor de N-mineral $\left(\mathrm{N}_{\text {min }}\right)$ e a mineralização líquida $\left(\mathrm{N}_{\text {liq }}\right)$, que indica se houve predomínio da mineralização do $\mathrm{N}$ (valor positivo) ou da sua imobilização (valor negativo) (Giacomini, 2005). Para melhorar a interpretação dos resultados de $\mathrm{N}$ obtidos nos experimentos de incubação, são utilizados modelos de simulação, como aquele que considera um único reservatório de N mineralizável no solo (Stanford \& Smith, 1972), o que possibilita determinar a fração do $N$ orgânico $\left(\mathrm{N}_{\text {org }}\right)$ potencialmente mineralizável e a constante de mineralização (k) (Camargo et al., 1997). Este trabalho objetivou avaliar a mineralização do $\mathrm{N}$ da massa de espé- 
cies de plantas de cobertura de inverno, solteiras e consorciadas, em um solo com histórico de cultivo de cebola.

\section{MATERIAL E MÉTODOS}

Em julho de 2011, na área do experimento intitulado Rendimento de cebola e atributos químicos de solo cultivado com plantas de cobertura sob SPD, instalado em julho de 2009 e localizado na Estação Experimental da Empresa de Pesquisa Agropecuária de Santa Catarina (Epagri), no município de Ituporanga (SC), foi coletada a parte aérea de plantas de cobertura, solteiras e consorciadas: aveia preta, centeio, nabo-forrageiro, aveia preta +nabo-forrageiro e centeio +nabo-forrageiro. Em seguida, a massa verde das plantas de cobertura foi secada em estufa com circulação de ar forçado, a $65{ }^{\circ} \mathrm{C}$, até massa constante. A MS foi pesada, determinada sua produção por hectare e reservada em duas partes. Nos tratamentos consorciados, a MS foi determinada separadamente para cada espécie. Uma primeira parte foi submetida à análise química (Tabela 1), enquanto a segunda parte das amostras de tecido foi cortada, manualmente, em tamanho de, aproximadamente, 1 a $2 \mathrm{~cm}$, como proposto por Giacomini et al. (2008) e, em seguida, foi reservada. No mesmo experimento, em outubro de 2011, foram coletadas, na camada de 0-10 cm, amostras de um Cambissolo Húmico (Embrapa, 2006), que apresentava os seguintes atributos: $300 \mathrm{~g} \mathrm{~kg}^{-1}$ de argila; 40,8 $\mathrm{g} \mathrm{kg}^{-1}$ de matéria orgânica; 23,58 $\mathrm{g} \mathrm{kg}^{-1} \mathrm{de}$ carbono orgânico total; $\mathrm{pH}$ em água de 6,$16 ; 145,2 \mathrm{mg} \mathrm{kg}$ ${ }^{1}$ de $\mathrm{P}$ disponível e $276 \mathrm{mg} \mathrm{kg}^{-1}$ de $\mathrm{K}$ trocável (extrator Mehlich 1); 7,18 $\mathrm{cmol}_{\mathrm{c}} \mathrm{kg}^{-1} \mathrm{de} \mathrm{Ca}, 3,38 \mathrm{cmol}_{\mathrm{c}} \mathrm{kg}^{-1} \mathrm{de} \mathrm{Mg}$ e $0,0 \mathrm{cmol}_{\mathrm{c}} \mathrm{kg}^{-1}$ de Al trocáveis (extrator $\mathrm{KCl} 1 \mathrm{~mol} \mathrm{~L}^{-1}$ ); 359,6

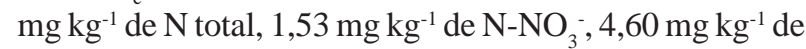
$\mathrm{N}-\mathrm{NH}_{4}^{+}$, relação $\mathrm{C} / \mathrm{N}=11,65$ e capacidade de troca de cátions $\left(\mathrm{CTC}_{\text {efetiva }}\right)$ de $11,26 \mathrm{cmol}_{\mathrm{c}} \mathrm{kg}^{-1}$. Posteriormente, $\mathrm{o}$ solo foi passado em peneira com malha de $4 \mathrm{~mm}$ e corrigida a umidade para $80 \%$ da capacidade de campo. Logo depois, $102,75 \mathrm{~g}$ de solo foram adicionados em recipientes de acrílico, em duas etapas, sendo cada amostra compactada (para maior uniformização da densidade). $\mathrm{O}$ volume final de solo em cada recipiente foi de $100 \mathrm{~mL}$ e, com isso, obteve-se a densidade de $1,02 \mathrm{~g} \mathrm{~cm}^{-3}$, semelhante àquela verificada no solo cultivado com cebola.

Com o material de plantas de cobertura reservados, foram constituídos seis tratamentos: solo (T1), aveia preta (T2), centeio (T3), nabo-forrageiro (T4), aveia preta+nabo-forrageiro (T5) e centeio+nabo-forrageiro (T6). Foram adicionados à superfície do solo conforme os tratamentos, em cada recipiente de acrílico, 1,65 g MS de aveia preta, 1,55 g MS de centeio, 1,60 g MS de naboforrageiro, 2,07 g MS de aveia preta+nabo-forrageiro e 2,18 g MS de centeio+nabo-forrageiro, quantidade equivalente a $0 \mathrm{~kg} \mathrm{ha}^{-1}$ de MS no tratamento T1, $3.203 \mathrm{~kg} \mathrm{ha}^{-1}$ de MS no T2, $1.304 \mathrm{~kg} \mathrm{ha}^{-1}$ de MS, no T3, $1.152 \mathrm{~kg} \mathrm{ha}^{-1} \mathrm{de}$ MS, no T4, $2.342 \mathrm{~kg} \mathrm{ha}^{-1}$ de MS no T5 e $2.825 \mathrm{~kg} \mathrm{ha}^{-1} \mathrm{de}$ MS, no T6. A quantidade de MS por hectare foi equivalente à obtida em cada espécie, solteira e consorciada, no campo. Em seguida, nove recipientes de acrílico, foram acondicionados aleatoriamente em frascos de $1.500 \mathrm{~mL}$, para evitar a perda excessiva de umidade. Imediatamente, foram armazenados em câmara de incubação, com temperatura constante de $17,6^{\circ} \mathrm{C}$, que é a temperatura média ao longo dos meses de setembro, outubro e novembro (Epagri, 2012), período correspondente do transplante até a bulbificação da cebola, na região de Ituporanga (SC), onde os resíduos das plantas de cobertura foram coletados. O delineamento experimental usado foi o inteiramente casualizado, com três repetições. A cada três dias, os recipientes com as unidades experimentais foram abertos, durante 15 minutos, em local arejado, para evitar a saturação de gases no seu interior. A umidade de cada unidade experimental foi monitorada diariamente através da pesagem da unidade amostral e, quando necessário, foi adicionada água destilada, para manter a capacidade de campo do solo a $80 \%$.

Tabela 1. Características químicas e bioquímicas dos resíduos de espécies de plantas de cobertura usados na incubação

\begin{tabular}{lrrrrr}
\hline Componentes da planta & Aveia preta & Centeio & Nabo-forrageiro & $\begin{array}{c}\text { Aveia preta + } \\
\text { nabo-forrageiro }\end{array}$ & $\begin{array}{c}\text { Centeio }+ \\
\text { nabo-forrageiro }\end{array}$ \\
\hline Celulose, \%(1) & 65,28 & 46,24 & 77,10 & 70,00 & 59,00 \\
Lignina, \%(1) & 34,72 & 53,76 & 22,90 & 29,99 & 41,99 \\
Relação celulose/lignina & 1,88 & 0,86 & 3,36 & 2,33 & 1,40 \\
Carbono orgânico total, \%(2) & 34,66 & 34,90 & 33,48 & 32,56 & 28,88 \\
N total, \%(2) & 1,55 & 1,33 & 2,46 & 1,91 & 1,77 \\
Relação lignina/N & 22,40 & 40,42 & 9,30 & 15,70 & 23,72 \\
Relação C/N & 22,36 & 26,24 & 13,60 & 17,04 & 16,31 \\
Cálcio total, \%(2) & 0,16 & 0,13 & 0,68 & 0,36 & 0,35 \\
Magnésio total, \%(2) & 0,15 & 0,11 & 0,09 & 0,12 & 0,10 \\
Potássio total, \%(2) & 1,05 & 0,85 & 0,76 & 0,95 & 0,81 \\
Fósforo total, \% & $(2)$ & 0,33 & 0,51 & 0,39 & 0,36
\end{tabular}

${ }^{(1)}$ Segundo metodologia proposta por Aber \& Martin (1999). (2) De acordo com metodologia proposta por Tedesco et al. (1995). 
No momento da instalação do experimento (tempo 0), e, aos 18, 36, 54, 72 e 90 dias depois do início da incubação, equivalente, aproximadamente, aos estádios fenológicos da cebola: transplante, $5^{\text {a }}$ folha verdadeira, $7^{\text {a }}$ folha verdadeira, formação da $8^{\mathrm{a}}$ à $14^{\mathrm{a}}$ folha, últimas folhas e bulbificação (Gandin et al., 2002), o solo foi retirado dos recipientes, homogeneizado e separado em duas porções. Uma porção de cinco gramas foi preparada e submetida à análise de $\mathrm{N}_{-} \mathrm{NH}_{4}^{+}$e N-NO${ }_{3}^{-}$(Tedesco et al., 1995). A segunda porção foi preparada e submetida à determinação da umidade e, com isso, o teor de $\mathrm{N}$ foi expresso em $\mathrm{mg} \mathrm{N}$ $\mathrm{kg}^{-1}$ de solo seco. $\mathrm{O} \mathrm{N}$ na forma de nitrito $\left(\mathrm{N}^{-\mathrm{NO}_{2}}{ }^{-}\right)$nas amostras de solos foi desprezado porque, em pré-testes, seus teores foram muito pequenos nos tratamentos.

A partir dos teores de $\mathrm{N}_{-} \mathrm{NH}_{4}{ }^{+} \mathrm{e} \mathrm{N}-\mathrm{NO}_{3}{ }^{-}$foi calculado o teor de $\mathrm{N}$-mineral $\left(\mathrm{N}_{\text {min }}\right): \mathrm{N}_{\text {min }}=\mathrm{N}_{-} \mathrm{NH}_{4}{ }^{+}+\mathrm{N}^{-} \mathrm{NO}_{3}{ }^{-}$. A evolução da taxa de mineralização de $\mathrm{N}$ dos diferentes tratamentos, ao longo da incubação, foi avaliada por meio da mineralização líquida, $\left(\mathrm{N}_{\mathrm{liq}}\right): \mathrm{N}_{\text {liq }}=\mathrm{N}_{\text {min }}$ solo do tratamento - $\mathrm{N}_{\text {min }}$ do solo testemunha, em que: $\mathrm{N}_{\text {liq }}=$ mineralização

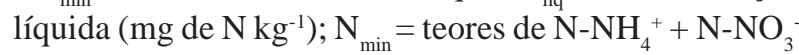
em cada tempo avaliado ( $\left.\mathrm{mg} \mathrm{de} \mathrm{N} \mathrm{kg}^{-1}\right)$. $\mathrm{A} \mathrm{N}_{\text {liq }}$ indica se houve predomínio da mineralização do $\mathrm{N}$ (valor positivo), ou da sua imobilização (valor negativo), em cada tempo de coleta e para cada combinação solo-resíduo (Giacomini, 2005). A cinética de mineralização, os potenciais de mineralização (No) e a constante de mineralização (k) de $\mathrm{N}$ foram obtidos a partir dos valores acumulados de $\mathrm{N}_{\text {min }}$ durante o período de incubação e foram ajustados pelo modelo matemático de progressão não linear. O potencial de mineralização (No) foi determinado por meio da equação $\mathrm{N}_{\text {total }}-\mathrm{Nm}$ no resíduo, em cada data de avaliação, em que $\mathrm{N}_{\text {total }} \mathrm{N}$ total adicionado por via do resíduo (mg de $\mathrm{N} \mathrm{kg}^{-1}$ ) e $\mathrm{Nm}$ foi obido pelo ajuste do modelo Stanford \& Smith (1972) (mg de $\mathrm{N} \mathrm{kg}^{-1}$ ), conforme descrito acima. O modelo citado considera apenas uma fração do $\mathrm{N}$ orgânico $\left(\mathrm{N}_{\text {org }}\right)$ do solo, que é potencialmente mineralizável, e o processo de mineralização segue uma cinética de primeira ordem, sendo definido pela equação exponencial simples, $\mathrm{Nm}=\mathrm{No}\left(1-\mathrm{e}^{-\mathrm{kt}}\right)$, em que: $\mathrm{Nm}=\mathrm{N}$ mineralizado acumulado em um período de tempo ( $\mathrm{mg}$ de $\mathrm{N} \mathrm{kg}^{-1}$ ); No = potencial de mineralização do $\mathrm{N}$ (mg de $\mathrm{N}$ $\left.\mathrm{kg}^{-1}\right) ; \mathrm{k}=$ constante de mineralização $\left(\operatorname{dia}^{-1}\right)$ e $\mathrm{t}=\mathrm{o}$ tempo (dias). A redução do No, função da mineralização (No $\mathrm{Nm}$ ) em cada evento foi determinada com os dados obtidos ajustados no modelo proposto por Stanford \& Smith (1972). Os resultados obtidos ao longo do período de incubação foram submetidos à análise de variância (ANOVA) e, quando significativos em relação aos tratamentos, foi realizada a análise de regressão, utilizandose equação polinomial, com significância de 5\%. Quanto à época, as médias entre tratamentos foram comparadas pelo teste de Tukey $(\alpha=5 \%)$.

\section{RESULTADOS E DISCUSSÃO}

Os teores de $\mathrm{N}-\mathrm{NH}_{4}^{+}, \mathrm{N}_{-} \mathrm{NO}_{3}{ }^{-}, \mathrm{N}$-mineral, N-mineral líquido e $\mathrm{N}$-mineralizado no solo foram influenciados pela cultura de cobertura, pelos dias de incubação (DAI) e pela interação entre cultura e dias após a incubação.

O teor de $\mathrm{N}_{-} \mathrm{NH}_{4}{ }^{+}$no solo diminuiu de forma quadrática, ao longo dos dias de incubação, em todos os tratamentos (Figura 1A). Os teores de $\mathrm{N}_{-} \mathrm{NH}_{4}^{+}$no tempo zero foram maiores no solo com a deposição de nabo-forrageiro, comparativamente aos teores no solo com a adição de aveia preta+nabo-forrageiro, aveia preta e solo sem adição de material vegetal. Entretanto, os teores de $\mathrm{N}_{-} \mathrm{NH}_{4}{ }^{+}$no solo com nabo-forrageiro foram iguais aos verificados no solo com a deposição de centeio+nabo-forrageiro e centeio. Aos 18 DAI, os teores de $\mathrm{N}_{-} \mathrm{NH}_{4}{ }^{+}$no solo com a deposição de nabo-forrageiro foram maiores que os observados no solo com a adição de aveia preta e do solo sem adição de material vegetal. Porém, os teores de $\mathrm{N}_{-} \mathrm{NH}_{4}{ }^{+}$no solo com a deposição de nabo-forrageiro não diferiram estatisticamente daqueles verificados no solo com a adição de centeio+nabo-forrageiro, centeio e aveia preta+naboforrageiro. Aos 36 DAI, o solo com a deposição de centeio+nabo-forrageiro apresentou maiores teores de $\mathrm{N}$ $\mathrm{NH}_{4}^{+}$, comparativamente ao observado no solo com a adição de de aveia preta+nabo-forrageiro, nabo-forrageiro, centeio, aveia preta e solo sem adição de material vegetal. Aos 54 DAI, os teores de $\mathrm{N}-\mathrm{NH}_{4}{ }^{+}$verificados no solo com a deposição de nabo-forrageiro foram maiores que os observados no solo com a deposição de aveia preta+naboforrageiro, centeio, aveia preta e solo sem adição de material vegetal. Contudo, o teor de $\mathrm{N}_{-} \mathrm{NH}_{4}{ }^{+}$no solo com a adição de nabo-forrageiro foi semelhante ao verificado no solo com a adição de centeio+nabo-forrageiro. Os teores de $\mathrm{N}_{-} \mathrm{NH}_{4}^{+}$, aos $72 \mathrm{DAI}$, do solo com a deposição de nabo-forrageiro foram maiores que os verificados no solo com a deposição de centeio+nabo-forrageiro, aveia preta+nabo-forrageiro, centeio, aveia preta e solo sem adição de material vegetal. Aos 90 DAI, os teores de N$\mathrm{NH}_{4}^{+}$no solo com a deposição de nabo-forrageiro foram maiores que os observados no solo com a deposição de aveia preta e solo sem adição de material vegetal. Porém, o teor de $\mathrm{N}_{-} \mathrm{NH}_{4}{ }^{+}$no solo com a adição de nabo-forrageiro foi semelhante ao verificado no solo com a deposição de centeio+nabo-forrageiro, centeio e aveia preta+naboforrageiro.

$\mathrm{O}$ teor de $\mathrm{N}-\mathrm{NO}_{3}{ }^{-}$aumentou de forma quadrática, no solo, ao longo dos dias de incubação (Figura 1B). Os teores de $\mathrm{N}_{-} \mathrm{NO}_{3}{ }^{-}$no solo, no tempo zero, foram semelhantes em todos os tratamentos. Aos $18 \mathrm{DAI}$, os teores de N$\mathrm{NO}_{3}^{-}$, no solo com a deposição de centeio+nabo-forrageiro, foram maiores que os observados nos solos com a deposição de aveia preta+nabo-forrageiro, aveia preta e solo 

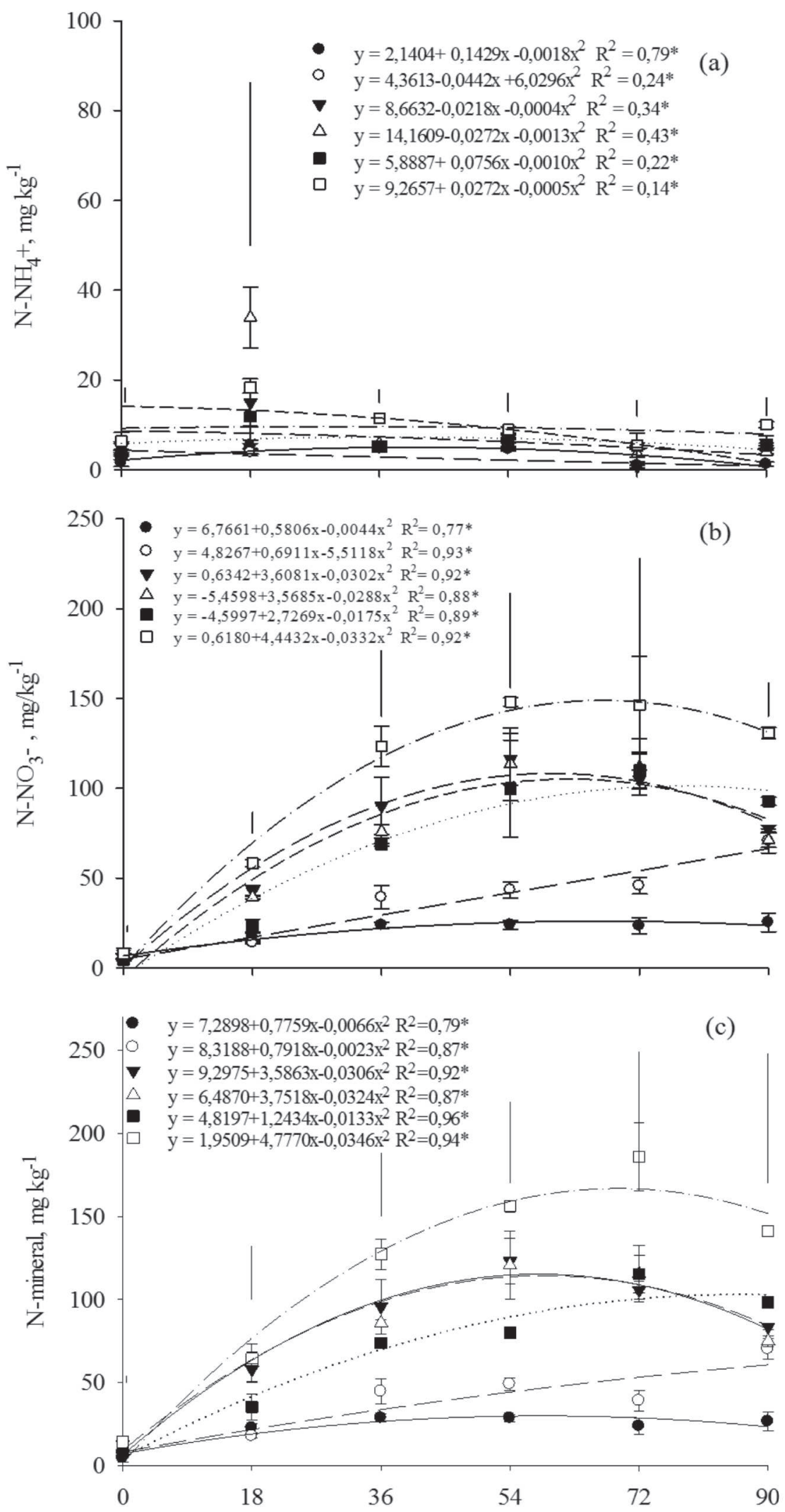

Dias após a incubação

Aveia preta

O Solo

$\boldsymbol{\nabla}$ Centeio

$\Delta$ Nabo forrageiro

- Aveia preta + Nabo forrageiro

口Centeio + Nabo forrageiro

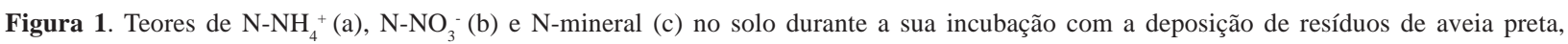
centeio e nabo-forrageiro, solteiros e consorciados. $(*=$ Significativo a $5 \%$ de probabilidade; em cada data as barras verticais indicam a diferença mínima significativa pelo teste de Tukey a 5\%). 
sem adição de material vegetal (Figura 1B). Entretanto, os teores de $\mathrm{N}_{-} \mathrm{NO}_{3}{ }_{3}^{-}$no solo com deposição de centeio+naboforrageiro foram semelhantes aos verificados no solo com a deposição de apenas nabo-forrageiro e centeio. Já, aos 36 DAI, o solo com a deposição de centeio+naboforrageiro apresentou os maiores teores de $\mathrm{N}-\mathrm{NO}_{3}{ }^{-}$. Nesta mesma coleta, aos 36 dias, os teores nos solos que receberam centeio, nabo-forrageiro e aveia preta+naboforrageiro não diferiram entre si, tendo-se, porém, observado teores de $\mathrm{N}_{-} \mathrm{NO}_{3}{ }^{-}$mais elevados que os verificados no solo com deposição de aveia preta e sem adição de material vegetal.

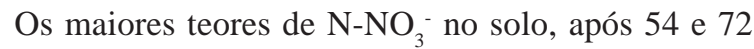
dias de incubação, foram verificados no solo com a deposição de centeio+nabo-forrageiro, comparados com os dos solos dos tratamentos com deposição de aveia preta e do tratamento sem adição de material vegetal (Figura 1B). Porém, os teores foram semelhantes, quando comparados com os dos solos dos tratamentos com a deposição de nabo-forrageiro, centeio e aveia preta+nabo-forrageiro.

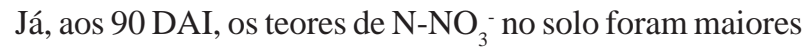
no tratamento com a deposição de centeio+naboforrageiro, comparados com os teores verificados nos tratamentos com a adição de aveia preta+nabo-forrageiro, nabo-forrageiro, centeio, aveia preta e do solo sem adição de material vegetal.

$\mathrm{O}$ teor de $\mathrm{N}$-mineral aumentou de forma quadrática no solo, ao longo dos dias de incubação (Figura 1C). Os teores de $\mathrm{N}$-mineral no solo, no tempo zero, foram maiores no tratamento com a deposição de centeio+nabo-forrageiro, comparados com os verificados nos tratamentos com a deposição de nabo-forrageiro, aveia preta+naboforrageiro, centeio, aveia preta e solo sem adição de material vegetal (Figura 1C). Aos 18, 36 e 54 DAI, os maiores teores de N-mineral no solo foram observados nos tratamentos com a deposição de centeio+nabo-forrageiro, em comparação com os observados nos tratamentos com a deposição de aveia preta e solo sem adição de material vegetal. Os teores de N-mineral no solo com a adição de centeio+nabo-forrageiro, entretanto, foram semelhantes aos verificados nos tratamentos com a adição de aveia preta+nabo-forrageiro e nabo-forrageiro e centeio. Aos 72 DAI, os teores de N-mineral no solo com a deposição de centeio+nabo-forrageiro foram maiores que os observados nos tratamentos com aveia preta e solo sem adição de material vegetal. Contudo, os teores de N-mineral, no solo com a deposição de centeio+nabo-forrageiro, não diferiram, estatisticamente, daqueles verificados nos solos dos tratamentos com a adição de aveia preta+naboforrageiro, nabo-forrageiro e centeio. Aos 90 DAI, os teores de N-mineral no solo com a deposição de centeio+nabo-forrageiro foram maiores que os verificados nos solos sem adição de material vegetal. Porém, os teores de N-mineral no solo com deposição centeio+naboforrageiro foram semelhantes aos verificados nos tratamentos com a deposição de aveia preta+nabo-forrageiro, nabo-forrageiro, centeio e aveia preta.

Os maiores teores de $\mathrm{N}-\mathrm{NH}_{4}{ }^{+}$no solo com a deposição de nabo-forrageiro, por exemplo, aos 18 DAI, comparados com os demais tratamentos são explicados por seu teor de $\mathrm{N}$ total, que proporciona menor valor de relação $\mathrm{C} /$ $\mathrm{N}$ (Tabela 1), que confere rápida decomposição dos resíduos e, por consequência, mineralização de $\mathrm{N}$ para o solo, o que pode incrementar os teores de $\mathrm{N}-\mathrm{NH}_{4}{ }^{+}$(Janssens et al., 2010). A diminuição dos teores de $\mathrm{N}_{-} \mathrm{NH}_{4}^{+}$, ao longo do tempo, em todos os tratamentos, com exceção daquele sem deposição de material vegetal, é atribuída, especialmente, à nitrificação do $\mathrm{N}_{-} \mathrm{NH}_{4}{ }^{+}$por micro-organismos nitrificadores (Geisseler et al., 2009), que causam o au-

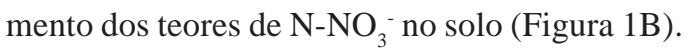

Os maiores teores de $\mathrm{N}^{-\mathrm{NO}_{3}}{ }_{3}^{-}$e de $\mathrm{N}$-mineral, no solo com a deposição de centeio+nabo-forrageiro, na maioria das coletas, são explicados, provavelmente, pela relação C/N do consórcio que foi de 16,31 (Tabela 1), que é menor que 20 e, por isso, estimula a mineralização (Azam et al., 1993; Chaves et al., 2004). Resultados similares foram obtidos por Neve et al. (2004), que relatam, em um experimento de incubação com a adição de plantas no solo, que a maior mineralização de $\mathrm{N}$ aconteceu no solo dos tratamentos com a deposição de material vegetal com menor relação $\mathrm{C} / \mathrm{N}$. No entanto, a maior mineralização de $\mathrm{N}$ no solo com a adição de centeio+nabo-forrageiro também é explicada, mesmo que em parte, pelos baixos teores de celulose e lignina, que proporcionaram um dos menores valores de relação celulose/lignina (Tabela 1) De acordo com Sanchez (2009), a lignina liga-se à celulose e à hemicelulose, formando uma barreira física na parede celular vegetal, promovendo resistência ao ataque microbiano. No entanto, em baixos valores da relação celulose/lignina, a decomposição do material vegetal é acelerada, proporcionando maior liberação de nutrientes logo após a deposição do material vegetal (Sainju et al., 2007) Ressalta-se que os menores teores de $\mathrm{N}_{-} \mathrm{NO}_{3}$ - e N-mineral no solo, especialmente nas últimas datas de coleta (72 e 90 DAI), foram obtidos no solo com a adição de aveia preta e isto é atribuído, provavelmente, à imobilização de formas de $\mathrm{N}$ (Vargas et al., 2005). Isso porque os teores de $\mathrm{N}-\mathrm{NO}_{3}{ }^{-}$e N-mineral foram menores que os observados no solo sem a deposição de material vegetal, e a aveia preta apresentava relação $\mathrm{C} / \mathrm{N}$ de 22,36 (Tabela 1) (Chaves et al., 2004).

Os teores de $\mathrm{N}$-mineral líquido $\left(\mathrm{N}_{\text {liq }}\right)$, no tempo zero, foram similares com e sem a deposição de material vegetal (Figura 2A). Aos 18, 36 e 54 DAI, os maiores teores de $\mathrm{N}_{\text {liq }}$ foram verificados nos solos com a deposição de centeio+nabo-forrageiro, comparados com solo com a 

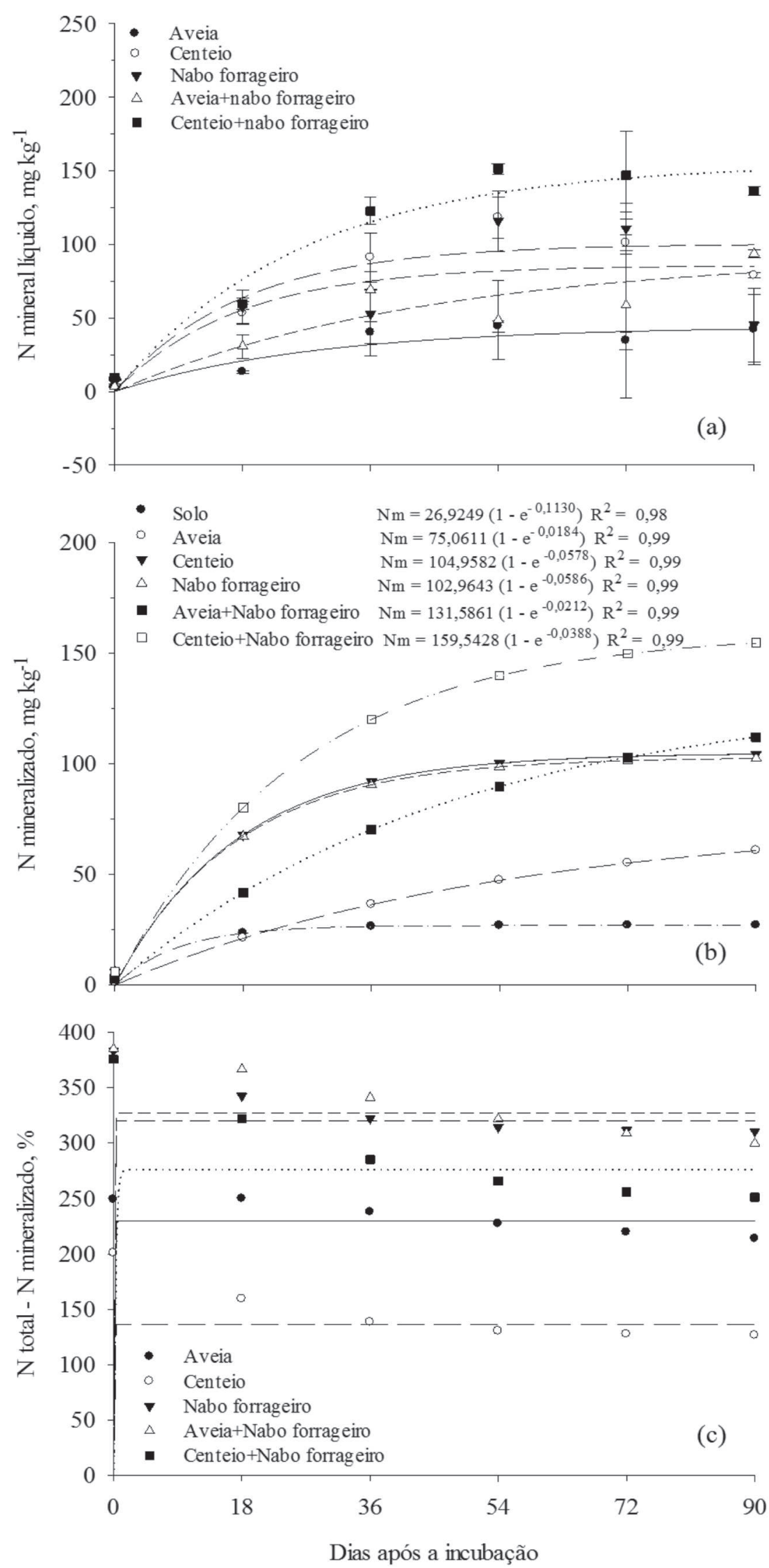

Figura 2. Teores de $\mathrm{N}$ mineral líquido (a), $\mathrm{N}$ mineralizado (b) e $\mathrm{N}$ total-N mineralizado (c) ( $\mathrm{mg} \mathrm{kg}^{-1}$ ) no solo com e sem deposição de resíduos durante a incubação (*= Significativo a 5\% de probabilidade; em cada data as barras verticais indicam a diferença mínima significativa pelo teste de Tukey a 5\%). 
adição de aveia preta e do solo sem material vegetal. Entretanto, os teores de $\mathrm{N}_{\text {liq }}$, no solo com deposição de centeio+nabo-forrageiro, não diferiram, estatisticamente, daqueles verificados nos solos com a adição de aveia preta+nabo-forrageiro, nabo-forrageiro e centeio. Aos 72 DAI, os teores de $\mathrm{N}_{\text {liq }}$, nos solos com a deposição de centeio+nabo-forrageiro, foram maiores que os observados nos solos com a deposição de aveia preta e solo sem adição de material vegetal. Contudo, os teores de $\mathrm{N}_{\text {liq }}$, no solo com deposição de centeio+nabo-forrageiro, foram semelhantes aos verificados nos solos com a adição de aveia preta+nabo-forrageiro, nabo-forrageiro e centeio. Aos 90 DAI, os teores de $\mathrm{N}_{\text {liq }}$, no solo com a deposição de centeio+nabo-forrageiro, foram maiores que os verificados no solo sem a deposição de material vegetal. Porém, os teores de $\mathrm{N}_{\text {liq }}$, no solo com deposição de centeio+nabo-forrageiro, foram semelhantes aos observados nos solos com a adição de aveia preta+naboforrageiro, nabo-forrageiro, centeio e aveia preta. Em todas as datas avaliadas, nos solos com a deposição de centeio, nabo-forrageiro, aveia preta+nabo-forrageiro e centeio+nabo-forrageiro, os valores de $\mathrm{N}_{\text {liq }}$ foram positivos, indicando a mineralização de N (Aita et al., 2004). Porém, no solo com a deposição de aveia preta, aos 18 e 72 DAI verificou-se valor de $\mathrm{N}_{\text {liq }}$ negativo, o que indica a imobilização de N (Souza et al., 2011; Fioreze et al., 2012) e, provavelmente, é explicado pelo valor da relação $\mathrm{C} / \mathrm{N}$ (Tabela 1).

No início da decomposição, principalmente nas espécies com maiores valores da relação $\mathrm{C} / \mathrm{N}$, como, por exemplo, neste estudo a aveia preta, ocorre um pico de imobilização pelos micro-organismos (imobilização maior que a mineralização), o que provoca o consumo de formas de Nmineral do solo, derivadas da decomposição de resíduos da matéria orgânica (Heinrichs et al., 2001). Assim, a imobilização microbiana de formas de $\mathrm{N}$ reduz a disponibilidade do nutriente para as plantas, como, por exemplo, a cebola. Porém, com o passar do tempo, ocorre o restabelecimento gradativo das transformações que acontecem no solo (imobilização igual à mineralização) e, a partir deste momento, os processos de transformação começam a liberar as formas de $\mathrm{N}$, ora imobilizado, para a solução do solo. No entanto, a imobilização de $\mathrm{N}$ também é associada ao valor de lignina do resíduo e até à relação celulose/lignina (Rasse et al., 2006; Heim \& Schmidt, 2007; Sanchez, 2009). Isso porque os micro-organismos apresentam menor capacidade de colonização de resíduos com maiores teores de lignina, o que diminui a liberação de N, aumentando a quantidade imobilizada, tanto que a relação lignina/N apresenta correlação negativa com a mineralização de N (Vanlauwe et al., 2005).

No tempo zero, os teores de $\mathrm{N}$-mineralizado (Nm), nos solos com e sem a deposição de material vegetal, não apresentaram diferença estatística (Figura 2B). Aos 18 DAI, o maior teor de $\mathrm{Nm}$ foi verificado no solo com a deposição de centeio+nabo-forrageiro, comparado com os observados nos solos com a adição de aveia preta+naboforrageiro, aveia preta e solo sem adição de material vegetal. Entretanto, o teor de Nm, no solo com deposição de centeio+nabo-forrageiro, não diferiu, estatisticamente, daquele observado no solo com a adição de centeio e nabo-forrageiro. Aos 36, 54, 72 e 90 DAI, os teores de Nm, no solo com a deposição de centeio+nabo-forrageiro, foram maiores que os observados nos solos com a deposição de aveia preta+nabo-forrageiro, nabo-forrageiro, centeio, aveia preta e no solo sem a deposição de material vegetal. Porém, os teores de Nm, nos solos, com deposição de aveia preta+nabo-forrageiro, nabo-forrageiro e centeio foram semelhantes (Figura 2B).

O modelo exponencial simples, proposto por Stanford $\&$ Smith (1972) (Figura 2B), ajustou adequadamente os resultados de $\mathrm{Nm}$, em geral, similares aos de $\mathrm{N}_{\min }$ no tempo zero e, aos 18, 36, 54 e $72 \mathrm{DAI}$, e estimou valores de No similares ao $\mathrm{N}_{\min }$ aos 90 dias (Figura 1C). Esses resultados concordam com os obtidos por Camargo et al. (1997), que, em dez solos representativos do Rio Grande do Sul e incubados durante 224 dias sem aplicação de N, relatam que o modelo estimou adequadamente os valores de No, com os valores de No ligeiramente inferiores aos de $\mathrm{N}_{\text {min }}$ acumulado aos 224 dias. O valor de No foi maior no solo com a deposição de centeio+nabo-forrageiro $(159,54 \mathrm{mg}$ de $\mathrm{N} \mathrm{kg}^{-1}$ ), em relação aos dos tratamentos com deposição de aveia preta+nabo-forrageiro $\left(131,58 \mathrm{mg} \mathrm{de} \mathrm{Ng}^{-1}\right)$, cen-

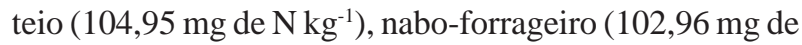
$\left.\mathrm{N} \mathrm{kg}^{-1}\right)$, aveia preta $\left(75,06 \mathrm{mg}\right.$ de $\left.\mathrm{N} \mathrm{kg}^{-1}\right)$ e solo sem a

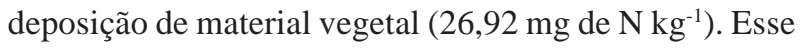
comportamento é atribuído ao consórcio utilizado no tratamento centeio+nabo-forrageiro, que causou aumento do teor de $\mathrm{N}$ total no tecido $(1,77)$ e diminuiu os valores da relação C/N (16,33) (Cabrera et al., 2005) (Tabela 1).

O solo com a deposição de aveia preta, aveia preta+nabo-forrageiro, centeio+nabo-forrageiro, centeio, nabo-forrageiro e sem a deposição de material vegetal apresentaram k de 0,0184; 0,0212; 0,0388; 0,0576; 0,0578 e 0,1130 , respectivamente (Figura $2 \mathrm{~B}$ ). Os maiores valores de k, nos solos sem a deposição de material vegetal, podem ser atribuídos ao teor de $\mathrm{N}$ total existente no solo e à sua baixa relação $(\mathrm{C} / \mathrm{N}=11,65)$.

Ao longo do período de incubação a deposição de espécies de plantas de cobertura, solteiras e consorciadas na superfície do solo, que correspondeu do transplante até a bulbificação da cebola, observou-se, especialmente nos solos com deposição de centeio, naboforrageiro, aveia preta+nabo-forrageiro e centeio+naboforrageiro, aumento da disponibilidade de $\mathrm{N}$-mineral, em especial, por causa do aumento dos teores de $\mathrm{N}_{-} \mathrm{NO}_{3}{ }^{-}$, 
que foram em todos os dias de incubação maiores que os teores de $\mathrm{N}_{-} \mathrm{NH}_{4}^{+}$. Mas, os maiores teores de $\mathrm{N}$-mineral foram verificados no solo com a deposição do consórcio de centeio+nabo-forrageiro, que apresentou, especialmente, valores intermediários de lignina e relação $\mathrm{C} / \mathrm{N}$, em relação aos dos tratamentos aveia preta, centeio, aveia preta+nabo-forrageiro. Assim, espera-se que cebolas cultivadas em solos com a deposição de centeio+naboforrageiro se beneficiem de maior disponibilidade de N, o que contribui positivamente para seu crescimento e produção (Souza et al., 2013). Além disso, a maior disponibilidade de N, no solo com a deposição de centeio+naboforrageiro, foi reforçada pelos maiores valores de $\mathrm{N}_{\text {liq }}$ e Nmineralizado, o que representa maior mineralização de $\mathrm{N}$. Somando-se a isso, também no solo com deposição de centeio+nabo-forrageiro verificaram-se os maiores valores do potencial de mineralização de $\mathrm{N}$, definido como a fração do N orgânico susceptível à mineralização (Stanford \& Smith, 1972).

\section{CONCLUSÕES}

Os maiores teores de amônio, ao longo do experimento, que correspondeu do transplante até a bulbificação da cebola, foram observados nos solos com a deposição de nabo-forrageiro e do consórcio centeio+nabo-forrageiro.

Os maiores teores de nitrato e N-mineral, dos 36 até os 90 DAI, e de N-mineralizado, dos 18 até os 92 DAI, foram observados no solo com a deposição de centeio+naboforrageiro, correspondendo aos estádios de transplante até a bulbificação da cebola.

A taxa de mineralização foi positiva, em todas as datas de coleta, nos solos com deposição de centeio, naboforrageiro e dos consórcios aveia preta+nabo-forrageiro e centeio+nabo-forrageiro. Mas, no solo com a deposição de aveia preta, os valores de N-líquido foram negativos aos 18 e 72 DAI, indicando imobilização de N.

A massa de nabo-forrageiro e o consórcio centeio+nabo-forrageiro apresentaram o maior potencial de mineralização, conferindo maior disponibilidade de $\mathrm{N}$ para a cebola, ao longo do seu ciclo.

Os valores da constante de mineralização (k) sugerem que a massa de aveia preta libera lentamente o nitrogênio para o solo cultivado com cebola.

\section{AGRADECIMENTOS}

À FAPESC, ao CNPq e à Capes pelas bolsas concedidas e recursos financeiros disponibilizados. Ao CNPq, pela concessão de bolsa em produtividade em pesquisa ao terceiro, quarto e sexto autor. À Estação Experimental da Empresa de Pesquisa Agropecuária de Santa Catarina (Epagri), em Ituporanga (SC), pela disponibilidade da área experimental.

\section{REFERÊNCIAS}

Aita C, Giacomini SJ, Hübner AP, Chiapinotto IC \& Fries MR (2004) Consorciação de plantas de cobertura antecedendo o milho em plantio direto. I - dinâmica do nitrogênio no solo. Revista Brasileira de Ciência do Solo, 28:739-749.

Azam F, Smith DC, Steward GF \& Hagström ^ (1993) Bacteriaorganic matter coupling and its significance for oceanic carbon cycling. Microbial Ecology, 28:167-179.

Benbi D \& Richer J (2002) A critical review of some approaches to modeling nitrogen mineralization. Biology and Fertility of Soils, 35:168-183.

Bonanomi G, Incerti G, Giannino F, Mingo A, Lanzotti V \& Mazzoleni S (2013) Litter quality assessed by solid state ${ }^{13} \mathrm{C}$ NMR spectroscopy predicts decay rate better than $\mathrm{C} / \mathrm{N}$ and Lignin/N ratios. Soil Biology \& Biochemistry, 56:40-48.

Cabrera ML, Kissel DE \& Vigil MF (2005) Nitrogen mineralization from organic residues: research opportunities. Journal Environment Quality, 34:75-79.

Camargo FAO, Gianello C \& Vidor C (1997) Potencial de mineralização do nitrogênio em solos do Rio Grande do Sul. Revista Brasileira de Ciência do Solo, 21:575-579.

Chaves B, De Neve S, Hofman G, Pascal B \& Cleemput OV (2004) Nitrogen mineralization of vegetable root residues and green manures as related to their (bio) chemical composition. European Journal of Agronomy, 21:161-170.

Dilly O, Blume HP \& Munch JC (2003) Soil microbial activities in Luvisols and Anthrosols during 9 years of region-typical tillage and fertilization practices in Northern Germany. Biogeochemistry, 65:284-299.

Embrapa - Empresa Brasileira de Pesquisa Agropecuária (2006) Centro Nacional de Pesquisa de Solos. Sistema brasileiro de classificação de solos. $2^{a}$ ed. Rio de Janeiro, Embrapa. 374p.

EPAGRI (2012) Recomendação de cultivares para o Estado de Santa Catarina. Florianópolis, EPAGRI. 142p. (Boletim Técnico, 72).

Fioreze C, Ceretta CA, Giacomini SJ, Trentin G \& Lorensini F (2012) Liberação do N em solos de diferentes texturas com ou sem adubos orgânicos. Ciência Rural, 42:1187-1192.

Flower KN, Cordingley PR, Warda C \& Weeksd (2012) Nitrogen, weed management and economics with cover crops in conservation agriculture in a Mediterranean climate. Field Crops Research, 132:63-75.

Gandin CL, Thomazelli LF \& Guimarães DR (2002) Estádios de desenvolvimento da cebola. Agropecuária Catarinense, 15:5356.

Geisseler D, Horwath WR \& Doane TA (2009) Significance of organic nitrogen uptake from plant residues by soil microorganisms as affected by carbon and nitrogen availability. Soil Biology \& Biochemistry, 41:1281-1288.

Giacomini SJ, Aita C, Miola ECC \& Recous S (2008) Mineralização do carbono da palha de aveia e dejetos de suínos aplicados na superfície ou incorporados ao solo. Revista Brasileira Ciência Solo, 32:2661-2668.

Giacomini SJ (2005) Avaliação e modelização da dinâmica de carbono e nitrogênio com o uso de dejetos de suínos. Tese de doutorado. Universidade Federal de Santa Maria, Santa Maria. 240 p.

Heim A \& Schmidt MWI (2007) Lignin turnover in arable soil and grassland analysed with two different labelling approaches. European Journal of Soil Science, 58:599-608. 
Heinrichs R, Aita C, Amado TJC \& Fancelli AL (2001) Cultivo consorciado de aveia e ervilhaca: relação $\mathrm{C} / \mathrm{N}$ da fitomassa $\mathrm{e}$ produtividade do milho em sucessão. Revista Brasileira de Ciência do Solo, 25:331-340.

Janssens IA, Dieleman W, Luyssaert S, Subke JA, Reichstein M, Ceulemans R, Ciais P, Dolman AJ, Grace J \& Matteucci G (2010) Reduction of forest soil respiration in response to nitrogen deposition. Nature Geoscience, 3:315-322.

Joanisse GD, Bradley RL \& Preston CM (2008) Do latesuccessional tannin-rich plant communities occurring on highly acidic soils increase the DON/DIN ratio? Biology and Fertility of Soils, 44:903-907.

Månsson KF \& Falkengren-Grerup U (2003) The effect of nitrogen deposition on nitrification, carbon and nitrogen mineralisation and litter C:N ratios in oak (Quercus robur L.) forests. Forest Ecology and Management, 179:455-467.

Meier EA, Thorburn PJ, Wegener MK \& Basford KE (2006) The availability of nitrogen from sugarcane trash on contrasting soils in the wet tropics of North Queensland. Nutrient Cycling in Agroecosystems, 75:101-114.

Mohanty M, Reddy KS, Probertc ME, Dalala RC, Raob AS \& Modelling NWM (2011) N mineralization from green manure and farmyard manure from a laboratory incubation study. Ecological Modelling, 222:719-726.

Neve SD, Sáez SG, Daguila BC, Sleutel S \& Hofman G (2004) Manipulating $\mathrm{N}$ mineralization from high $\mathrm{N}$ crop residues using on- and off-farm organic materials. Soil Biology \& Biochemistry, $36: 127-134$.

Rasse DP, Dignac MF, Bahri H, Rumpel CA, Mariotti A \& Chenu C (2006) Lignin turnover in an agricultural field: from plant residues to soil protected fractions. European Journal of Soil Science, 57:530-538

Sá JCM, Cerri CC, Lal R, Dick WA, Venzke filho SP, Piccol OM \& Feigl B (2001) Organic matter dynamics and sequestration rates for a tillage chronosequence in a Brazilian Oxisol. Soil Science Society of American Journal, 65:1486-1499.

Sainju UM, Schomberg HH, Singh BP, Whitehead WF, Tillman PG \& Lachnicht-Weyers SL (2007) Cover crop effect on soil carbon fractions under conservation tillage cotton. Soil Tillage Research, 96:205-218.

Sanchez C (2009) Lignocellulosic residues: biodegradation and bioconversion by fungi. Biotechnology Advances, 27:185-194.
Séguy L, Bouzinac S \& Husson O (2006) Direct-Seeded tropical soil systems with permanent soil cover: learning from Brazilian experience. In Uphoff $\mathrm{N}$ (Ed.) Biological approaches to sustainable soil systems. Boca Raton, Taylor and Francis Group. p.323-342.

Souza HÁ, Natale W, Modesto VC \& Rozane DE (2011) Mineralização do nitrogênio proveniente da aplicação do resíduo da indústria processadora de goiabas em Argissolo. Bragantia, 70:882-887.

Souza M, Comin JJ, Leguizamón ES, Kurtz C, Brunetto G, Júnior VM, Ventura B \& Camargo AP (2013) Matéria seca de plantas de cobertura, produção de cebola e atributos químicos do solo em sistema plantio direto agroecológico. Ciência Rural, 43:2127.

Stanford G \& Smith S (1972) Nitrogen Mineralization Potentials of Soils. Soil Science Society American Journal, 36:465-472.

Sylvia D, Fuhrmann J, Hartel P \& Zuberer D (2004) Principles and Applications of Soil Microbiology. $2^{\mathrm{a}}$ ed. New Jersey Prentice Hall. 672p.

Tedesco MJ, Gianello C, Bissani CA, Bohnen H \& Volkweiss SJ (1995) Análises de solo, plantas e outros materiais. Porto Alegre, Universidade Federal do Rio Grande do Sul. 174p. (Boletim Técnico, 5).

Thorpe AS, Aschehoug ET, Atwater DZ \& Callaway RM (2011) Interactions among plants and evolution. Journal of Ecology, 99:729-740

Trinsoutrot I, Recous S, Bentz B, Linères D, Chèneby D \& Nicolardot B (2000) Biochemical quality of crop residues and carbon and nitrogen mineralization kinetics under nonlimiting nitrogen conditions. Soil Science Society American Journal, 64:918-926.

Vahdat E, Nourbakhsh F \& Basiri M (2011) Lignin content of range plant residues controls $\mathrm{N}$ mineralization in soil. European Journal of Soil Biology, 47:243-246.

Vanlauwe B, Gachengo K, Shepherd E, Barrios G, Cadisch G \& Palm CA (2005) Laboratory validation of a resource qualitybased conceptual framework for organic matter management. Soil Science Society of America Journal, 69:1135-1145.

Vargas LK, Selbach PA \& Saccol de Sá EL (2005) Imobilização de nitrogênio em solo cultivado com milho em sucessão à aveia preta nos sistemas plantio direto e convencional. Ciência Rural, 35:76-83. 